\title{
Potential effects of subglacial water-pressure fluctuations on quarrying
}

\author{
NEAL R. IVERSON \\ Department of Geology and Geophysics, University of Minnesota, Minneapolis, Minnesota 55455, \\ U.S.A.
}

\begin{abstract}
Water-pressure fluctuations beneath glaciers may accelerate rock fracture by redistributing stresses on subglacial bedrock and changing the pressure of water in bedrock cracks. To study the potential influence of water-pressure fluctuations on the fracture of subglacial bedrock, ice flow over a small bedrock step with a water-filled cavity in its lee is numerically modeled, and stresses on the bedrock surface are calculated as a function of transient water pressures in the cavity. Stresses on the bed are then used to calculate principal stress differences within the step. Rapid reductions in cavity water pressure increase principal stress differences in the bed, increasing the likelihood of crack growth in the step and the formation of predominantly vertical fractures. Relatively impermeable bedrock may be most susceptible to fracturing during water-pressure reductions because high water pressure in cracks within the rock can be maintained, as water pressure decreases in cavities. These results, when considered in conjunction with the strong likelihood that increases in water pressure accelerate the removal of rock fragments loosened from the bed, suggest that in zones of ice-bed separation where waterpressure fluctuations typically are large, rates of quarrying may be higher than along other parts of glacier beds.
\end{abstract}

\section{INTRODUCTION}

It is well established that where ice separates from bedrock beneath glaciers large temporal variations in subglacial water pressure can occur. Basal water pressures have been measured directly in boreholes and moulins, and have sometimes been found to fluctuate diurnally through more than $0.5 \mathrm{MPa}$ (Kamb and others, 1985; Iken and Bindschadler, 1986; Hooke and others, $1987,1989)$. In addition to affecting the sliding velocity of glaciers, these pressure variations may play an important role in quarrying subglacial bedrock (Robin, 1976; Röthlisberger and Iken, 1981). The intent of this study was to explore this idea further by analyzing how the stresses exerted by ice and water on a small part of an idealized glacier bed are influenced by fluctuations in the water pressure within a nearby cavity.

As noted by Röthlisberger and Iken (1981), quarrying comprises several processes. Bedrock blocks must be first loosened from the bed by either subglacial rock fracture or by the presence of preglacial joints. They then have to be removed from the bed and entrained by basal ice. Here, the focus will be on the effects of water-pressure fluctuations on rock fracture. Stresses along the surface of a bedrock step are calculated for steady and transient water pressures in a subglacial cavity with the finiteelement method. The calculated stress distributions are used to determine stresses at depth within the bedrock, and the likelihood of fracture propagation in the rock is assessed with the Griffith failure criterion.

\section{ROCK FRACTURE}

\section{Background}

Quarrying can only occur if subglacial bedrock is sufficiently fractured. Many authors have noted the role of preglacial joints in the process (Matthes, 1930; Crosby, 1945; Zumberge, 1955; Addison, 1981; Rastas and Seppala, 1981). It is unlikely, however, that preglacial joints will always be dense and continuous enough to completely isolate bedrock blocks so that removal requires that only frictional forces be overcome. One might argue that preglacial weathering processes could create sufficiently fragmented bedrock, but this does not explain the erosion of valleys and fiords that are thousands of meters deep. Subglacial fracture must occur, therefore, to some extent. This is supported by observations of groups of boulders with quarried lee surfaces that are firmly embedded in lodgement tills (Sharp, 1982).

Morland and Morris (1977) examined the possibility that sliding ice might exert a sufficiently large viscous drag on bedrock obstacles to induce fracture. Using Nye's (1969) theoretical pressure distribution over the surface of a wavy bed, they solved for the stress field in an 
asymmetric, elastic bedrock hump. Using the Coulomb failure criterion and including the effect of pore-water pressure, they concluded that differences between the two effective principal stresses in the hump were generally not large enough to induce failure in intact bedrock.

The analysis presented in this section is similar to that of Morland and Morris (1977) in that stress fields in an elastic bedrock irregularity are calculated for a range of conditions, and the resultant tendency for fracture is assessed. However, important differences exist. Here, stresses are analyzed in an idealized bedrock step with a cavity in its lee. The effect of water-pressure variations in the cavity on the ice flow and on the pressure distribution along the rock surface is determined using a method similar to that used by Iken (1981). Because the macroscopic fracture of rock depends sensitively on poorly constrained variables like rock microstructure and environmental factors associated with sub-critical crack propagation (e.g. Atkinson, 1984), the main objective of this study is not to predict the exact conditions under which failure will occur. Instead, changes in the propensity for rock fracture will be evaluated for specified fluctuations in water pressure, assuming lesser-known variables remain constant.

\section{Ice flow over a bedrock step}

A finite-element program developed by Hanson (1985) is used to model ice flow over a step on the bed that is $1 \mathrm{~m}$ in height (Fig. 1). The chosen geometry, although simplified, is not unrealistic; planar bedrock steps have frequently been observed (Anderson and others, 1982; Hallet and Anderson, 1982). Given the necessary boundary conditions, the program calculates vertical and horizontal velocities at each node and the mean pressure within each element. Strain rates normal to the flow plane are assumed to be zero (plane strain). Equations

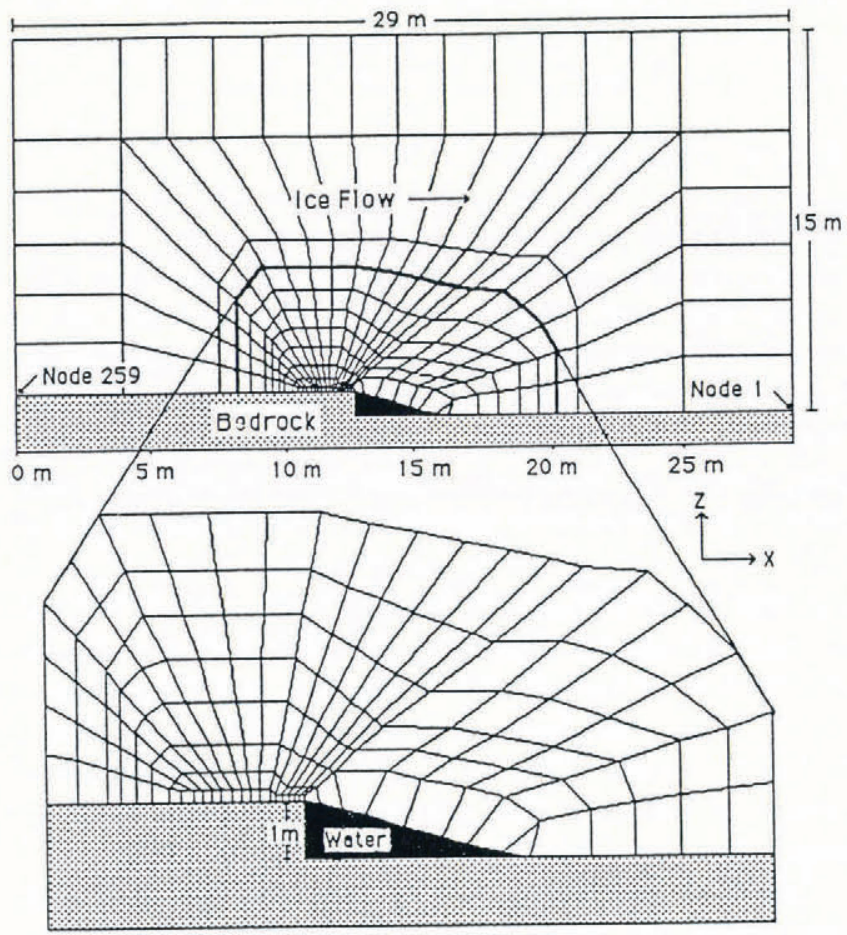

Fig. 1. Finite-element grid for the ice-flow calculation. The plane of the grid is vertical and parallel to the flow direction. solved are for continuity of an incompressible fluid and conservation of momentum when accelerations are negligible. The familiar Glen-type power law for flow is assumed:

$$
\dot{\epsilon}=(\tau / B)^{n}
$$

where $\dot{\epsilon}$ and $\tau$ are the effective strain rate and shear stress, respectively, $n$ is a constant taken to be equal to 3 , and $B$ is a temperature-dependent viscosity coefficient.

At nodes along the lower boundary of the domain, where the ice is in contact with the bed, the vertical ice velocity is fixed at zero. This constrains the direction of ice movement to be parallel to the ice-bed interface. The basal ice is assumed to contain no debris, so the effect of ice convergence with the bed on fragment-bed stresses (Hallet, 1979) is not considered. At nodes along the zone of ice-bed separation in the lee of the step, where the glacier sole is supported by water under pressure, a force normal to the cavity roof is specified. These are identical to the conditions specified by Iken (1981) in her numerical simulation of hydraulically jacked sliding over a wavy bed. The method used to determine the size of the separated zone is discussed below.

A normal stress and shear stress act on the upper boundary. A normal stress of $2.57 \mathrm{MPa}$ was chosen, equal to the pressure beneath $285 \mathrm{~m}$ of ice. A shear stress of 0.09 $\mathrm{MPa}$ was applied to the upper boundary, consistent with a glacier surface slope of $4^{\circ}$ and assuming that the basal shear stress is reduced by one-half to account approximately for the fraction of basal shear stress supported by valley walls (Nye, 1965).

Along the ends of the modeled section, forces are prescribed at each node commensurate with a pressure normal to the boundary equal to $\rho g H$ where $\rho$ is the ice density, $g$ is the gravitational acceleration, and $H$ is the overlying ice thickness. This is strictly true only for a fluid at rest sustaining no shear stresses. However, because the glacier surface slope is small, it is a good approximation. In addition, stresses normal to the boundary will deviate from $\rho g H$ if a velocity gradient across the length of the domain exists, implying a gradient in the longitudinal stress. Thus, for this to be a valid boundary condition, horizontal velocities calculated along the up-glacier side of the domain must approximately equal those calculated along the domain's down-glacier side. To maintain mechanical equilibrium, shear stresses must act on the ends of the modeled section. These shear stresses are not fixed as boundary conditions, but are produced during the balancing of forces during a given computation, as implied by velocity gradients in the resultant flow solutions. Finally, at the nodes located at the two lower outside corners of the section (nodes 1 and 259; Fig. 1), a reasonable sliding velocity parallel to the bed is specified. Note that the specification of a sliding velocity at the lower outside corners of the section and a shear stress along the upper boundary implies a rough bed. The roughness can be thought of as resulting from small-scale roughness elements on the planar surface.

\section{Modeling of a steady cavity}

The cavity that forms down-glacier from the bedrock step is steady if it is neither shrinking nor expanding at a given water pressure. This means that a parcel of ice on the cavity roof has a net velocity parallel to the cavity 
surface. A primary goal of this modeling is to determine the pressure distribution against the rock upstream from a steady cavity and then to examine how it is affected by transients in the cavity water pressure. In contrast, Iken (1981), who modeled water-pressurized cavities in the lee of sinusoidal bed undulations, was principally concerned with the effect of transients in cavity water pressure on the basal sliding velocity. The iterative method used to model steady cavities in this analysis therefore is different in some respects from the one used by Iken.

The iteration is begun by specifying a sliding velocity at each end of the domain (nodes 1 and 259), a water pressure in the cavity, and a reasonable cavity geometry. The program is then run and the velocity field examined. The velocity calculated at nodes along the cavity roof usually shows that the cavity is either expanding or shrinking, or expanding at some places and shrinking at others. Two changes are therefore made before the next iteration: (1) the geometry of the cavity is changed, as suggested by the velocity field, and (2) the velocity at the two lower, outside corners of the domain is increased if the cavity is shrinking or decreased if the cavity is expanding. By this iterative procedure the geometry of the cavity is adjusted until velocity vectors at nodes along the cavity wall are within $3^{\circ}$ the cavity surface. Thus, a cavity is obtained that has a size and geometry commensurate with the specified cavity water pressure and sliding velocity. The effect on the cavity geometry of viscous heat dissipation by subglacial water flow is not incorporated into the calculation, due to its dependence on a number of poorly constrained hydrological parameters. This effect, however, may be important, increasing the length of a steady-state cavity by as much as a factor of 3 (Kamb, 1987).

A steady cavity with an internal water pressure, $P_{\mathrm{w}}$, of $2.1 \mathrm{MPa}$ is shown in Figure 2 (solid line). The sliding velocity at the ends of the domain was $5.2 \mathrm{myear}^{-1}$. As expected, the ice pressure is concentrated on the area of the bed immediately upstream from the cavity. Pressure on the rock in this area is just over $4.0 \mathrm{MPa}$ or about $50 \%$ greater than the ambient mean pressure in the basal ice. Velocities at nodes along the up-glacier end of the domain are within $4 \%$ of velocities at nodes an equal distance above the bed along the down-glacier side of

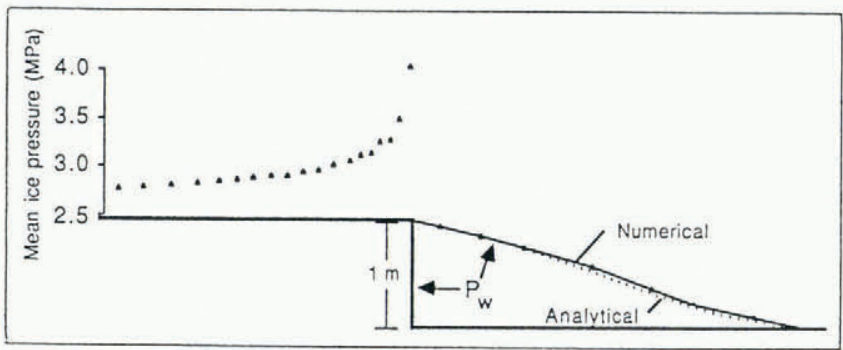

Fig. 2. Geometry of a steady cavity (solid line) and the mean ice pressure in elements along the bed. $P_{w}=2.1 \mathrm{MPa}, \mathrm{B}=0.28 \mathrm{MPa}$ year, the sliding velocity is 5.2 myear $^{-1}$, and the ice thickness is $300 \mathrm{~m}$. Dotted line is Kamb's (1987) analytical solution for the cavity geometry using a linear rheology, and assuming no melting occurs. the domain. Gradients in the longitudinal strain rate and stress over the domain length are therefore small. A value of $B=0.28 \mathrm{MPa}$ year ${ }^{\frac{1}{3}}$ was used in the calculation. The solution proved to be stable against a factor of 2 reduction in the size of the domain, and was also nearly identical to one obtained from Kamb's (1987) analytical solution for the geometry of a step cavity using a linear rheology with appropriately scaled viscosities (Fig. 2, dotted line).

A steady cavity was also calculated with a $B$ value of $0.176 \mathrm{MPa}$ year ${ }^{\frac{1}{3}}$, which is probably more appropriate for temperate ice (Hooke, 1981, fig. 2). In this case, a sliding velocity of about $19{\mathrm{~m} y e a r^{-1}}$ was necessary to produce a steady cavity of the same dimensions as that calculated with the larger $B$ value. This is consistent with the power-law relation for flow, which predicts a four-fold increase in the effective strain rate as a result of reducing $B$ from 0.28 to $0.176 \mathrm{MPa}$ year ${ }^{\frac{1}{3}}$. The stresses in the ice are the same in both cases, however, and thus the pressure distribution along the bed upstream from the cavity remains unchanged.

\section{Transient water pressures}

Any sudden decrease in the cavity water pressure will be accompanied by an increase in ice pressure against the bed, because the pressure averaged over the base of the glacier must remain constant. In the vicinity of the cavity, the magnitude of the change in ice pressure will depend on the geometry of the cavity and on the magnitude of the water-pressure change.

To examine the effects of transient water pressures, forces at nodes along the wall of the steady cavity $\left(P_{\mathrm{w}}=2.1 \mathrm{MPa}\right)$ were specified that are commensurate with water pressures of $2.5,1.9$ and $1.5 \mathrm{MPa}$. Other than these changes, boundary conditions were unchanged from the last iteration of the steady-cavity calculation. Keeping the sliding velocity at the domain ends at the steady value is incorrect, however, because increases or decreases in the cavity water pressure should affect the far-field sliding velocity (Iken, 1981). Horizontal components of the ice velocity are therefore not accurate in the transient calculations. However, the vertical component of the ice velocity at each node and, more importantly, the pressure distribution against the bed, are accurate because they are independent of the horizontal velocity specified at the domain ends.

Figure $3 \mathrm{~b}$ and $\mathrm{c}$ illustrate the effect of reductions in the cavity water pressure on the vertical component of the ice velocity at the cavity wall. Reducing the water pressure $0.6 \mathrm{MPa}$ results in about a five-fold increase in the downward component of the ice velocity relative to the steady case (Fig. 3a). Figure 4 shows the distribution of ice pressure over $1.5 \mathrm{~m}$ of the bed immediately upstream from the cavity for three different transient water pressures and for the steady-state water pressure. In the element nearest the cavity, a decrease in water pressure from the steady value results in an increase in ice pressure of roughly the same magnitude as the waterpressure decrease. The steps in the curves are products of the geometry of the elements chosen along the bedrock surface. Solutions using different element configurations are only slightly different, with steps occurring at different positions along the bed. 


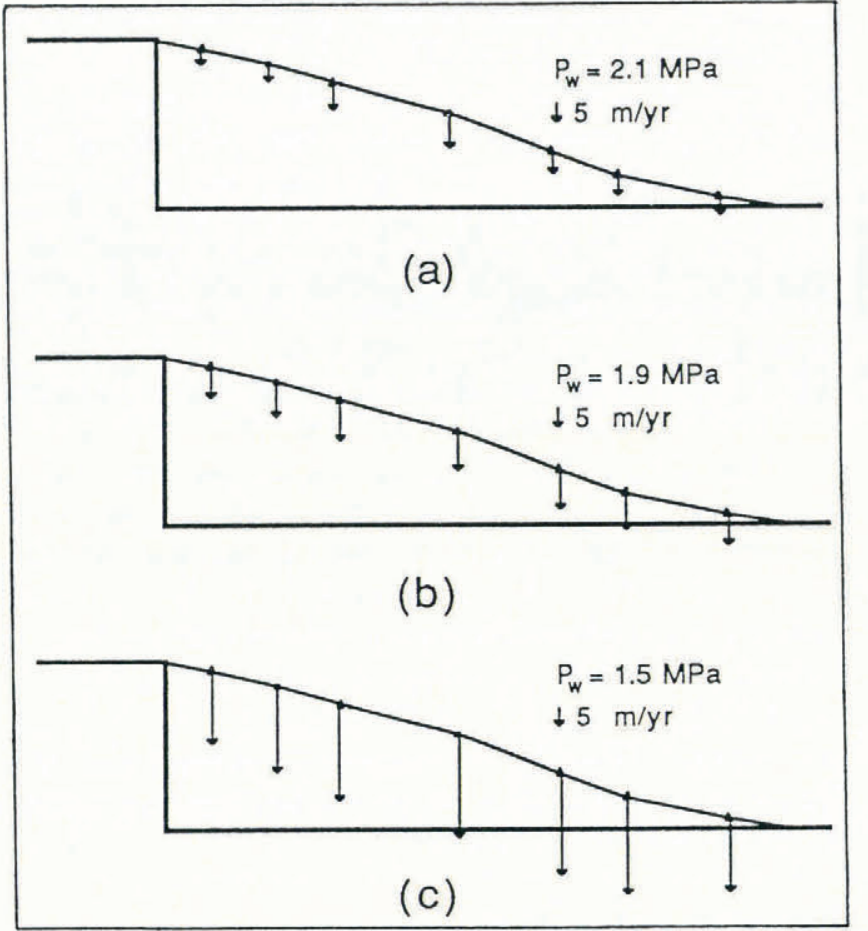

Fig. 3. The vertical component of the ice velocity at nodes along the cavity ceiling when the cavity is (a) steady at a water pressure of 2.1 MPa, and when the water pressure is instantaneously reduced to (b) $1.9 \mathrm{MPa}$ and (c) $1.5 \mathrm{MPa}$. When $P_{w}$ is raised to 2.5 MPa, downward vertical velocities are all less than 0.7 mear $^{-1}$.

The magnitude of the increase in ice pressure should depend on the extent of ice-bed separation (Robin, 1976, p. 192). If, for example, two cavities had been included at the base of the section rather than a single cavity, a given reduction in water pressure would have shifted a larger fraction of the weight of the glacier to zones of icebed contact, resulting in greater increases in ice pressure against the bed.

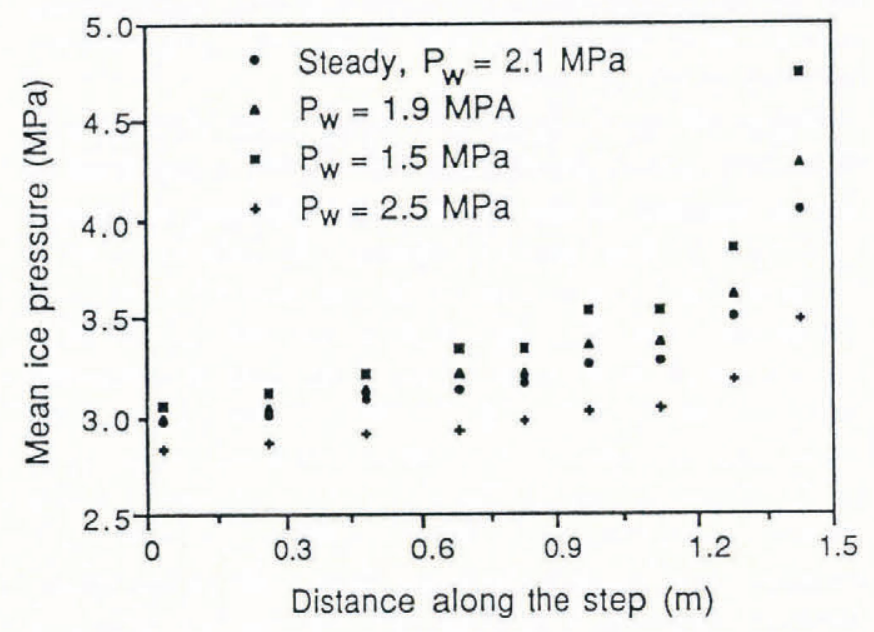

Fig. 4. Mean ice pressures in elements along the bed immediately upstream from the cavity (cavity edge at $1.5 \mathrm{~m}$ ) for steady and transient cavity water pressures.

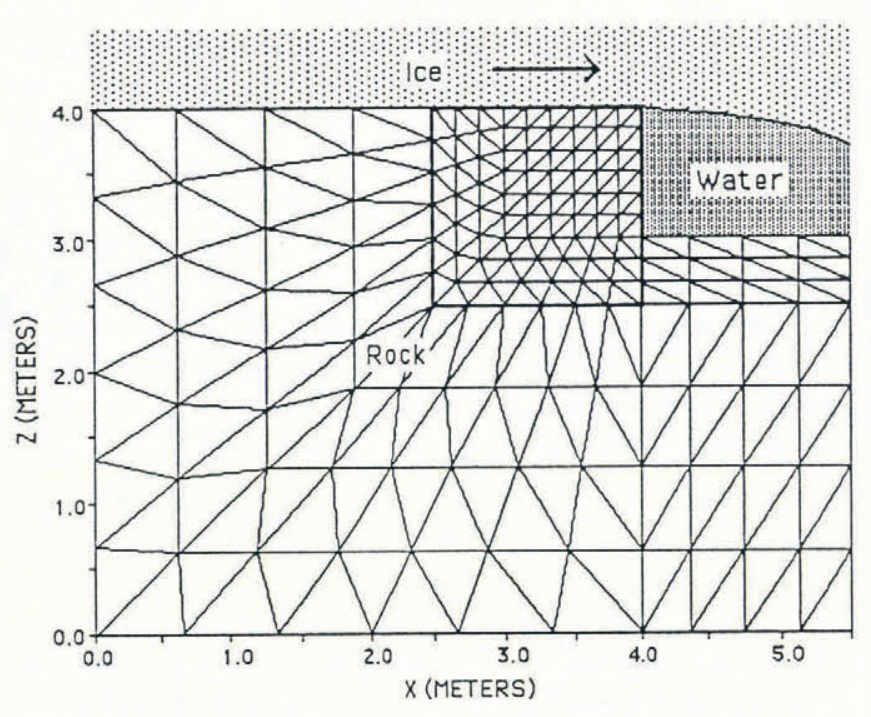

Fig. 5. Finite-element grid for calculating bedrock stresses in a vertical plane through the step, parallel to the direction of ice flow.

\section{Bedrock stresses}

For the steady cavity modeled above, reductions in the cavity water pressure result in increases in ice pressure against the bed upstream from the cavity, whereas increases in water pressure reduce this pressure (Fig. 4). To determine the effect of the pressure changes on the propensity for bedrock fracture, stress fields within the bedrock step must be calculated. A program developed by Gustafson and others (1977) is used to obtain a finiteelement approximation of the stress field. Linear elasticity and plane strain are assumed. A vertical plane through the bedrock step is discretized into triangular elements (Fig. 5) and, with appropriate boundary forces and displacements, the program calculates the magnitude and orientation of the principal stresses within each element. Elements are concentrated in a $1.5 \mathrm{~m}$ square where bedrock fracture associated with quarrying is expected. At nodes along the upper surface of the bed, normal forces are prescribed using the distributions of basal ice pressure calculated above. At nodes along the bed contained within the cavity, a normal force is specified that is commensurate with the water pressure in the cavity. Although a shear stress of $0.09 \mathrm{MPa}$ is supported along the bed in the ice-flow calculation, assigning boundary conditions along the ends of the modeled section is greatly simplified if a shear stress is not specified in the bedrock stress calculation. Neglecting the shear stress only slightly influences bedrock fracture because the shear stress is small relative to the difference between the normal stresses applied to the step's upper and lee surfaces. Along ends of the section, zero horizontal displacement is specified, which is equivalent to assuming that the horizontal stress, $\sigma_{x}$, at the ends of the section equals $\nu(1-\nu)^{-1} \rho g H$, where $\nu$ is Poisson's ratio (Jaeger and Cook, 1979 , p. 372). At nodes along the lower boundary, zero horizontal and vertical displacement are assumed.

Contours of the two principal stresses in a part of the step adjacent to the steady cavity $\left(P_{\mathrm{w}}=2.1 \mathrm{MPa}\right)$ are plotted as solid lines in Figure $6 \mathrm{a}$ and b. Both prin- 


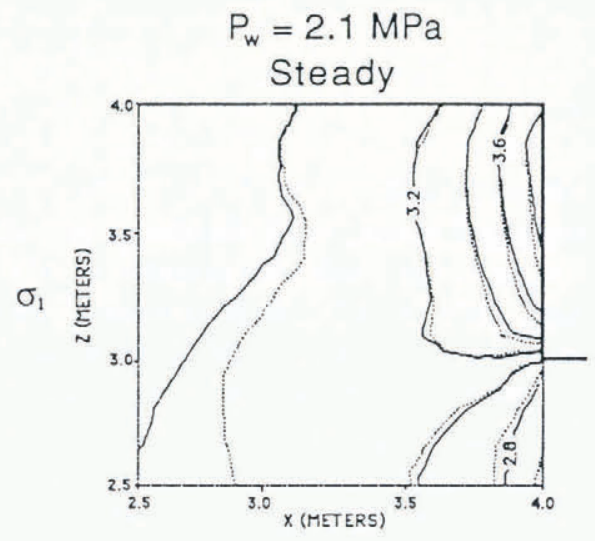

(a)

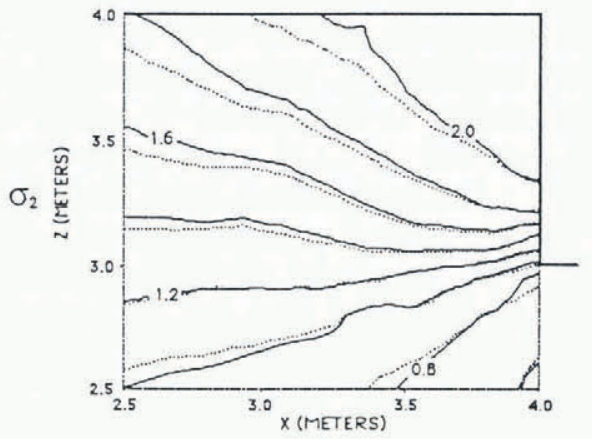

(b)

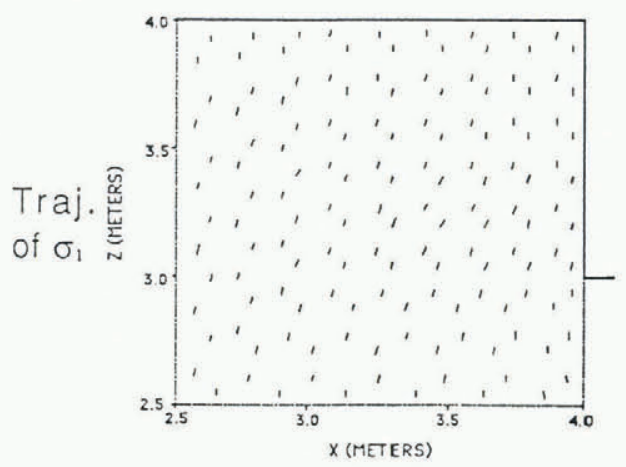

(c)

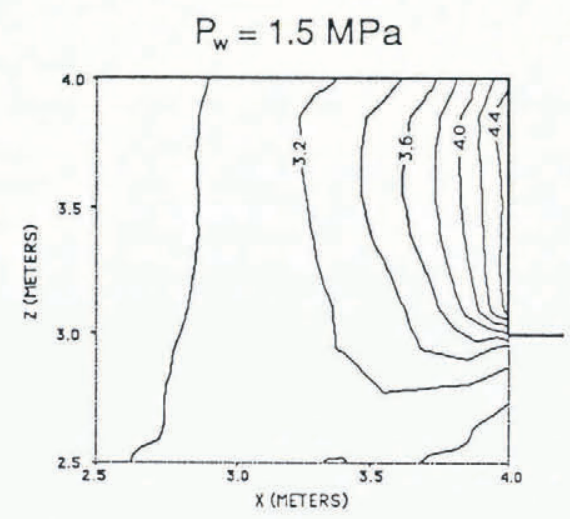

(d)

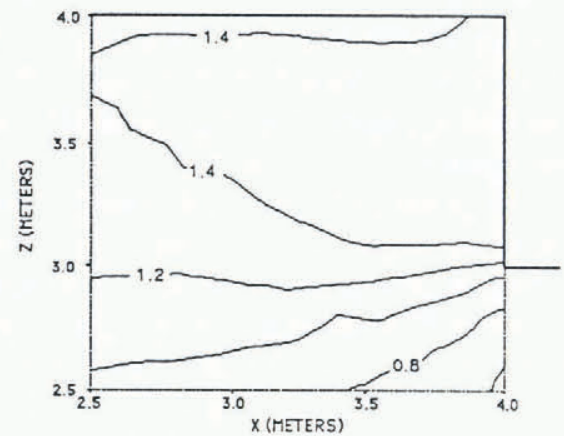

(e)

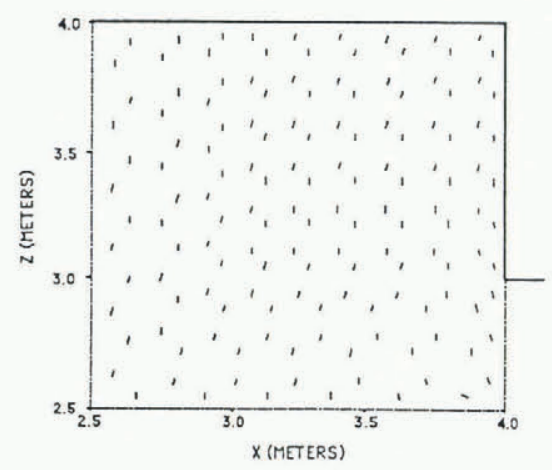

$(f)$

Fig. 6. Contours of (a) $\sigma_{1}$ and (b) $\sigma_{2}$ when the cavity is steady at a water pressure of $2.1 \mathrm{MPa}$ (solid lines). Dotted contours were calculated with an expanded modeling domain. (c) Trajectories of $\sigma_{1}$ when the cavity is steady. Contours of (d) $\sigma_{1}$ and (e) $\sigma_{2}$ when the cavity water pressure is reduced to $1.5 \mathrm{MPa}$. (f) Trajectories of $\sigma_{1}$ when the cavity water pressure is reduced to $1.5 \mathrm{MPa}$. Step surface is delineated with a bold line. Stresses are in MPa.

cipal stresses are compressive (positive); therefore, the greatest principal stress $\left(\sigma_{1}\right)$ is the one that is most compressive. $\sigma_{1}$ increases toward the cavity edge, reflecting the increase in ice pressure toward the cavity. $\sigma_{2}$ becomes less compressive away from the upper corner of the step where the ice pressure is highest. Gradients in both $\sigma_{1}$ and $\sigma_{2}$ are greatest near the base of the step. Trajectories (orientations) of $\sigma_{1}$ are nearly vertical or steeply dipping up-glacier (Fig. 6c). The same calculation using a domain that was $4 \mathrm{~m}$ longer and $3 \mathrm{~m}$ deeper yielded a similar stress distribution (Fig. 6a and b; dotted lines). Applying a $0.1 \mathrm{MPa}$ shear stress to the step surface upstream from the cavity likewise had only a small effect. Apparent deviations from applied boundary stresses along the step surface result from the finiteelement approximation, which limits the distance over which stress gradients can be resolved to the width of an element.

To calculate stress fields in the step for transient water pressures in the cavity, stresses along the upper surface of the domain were changed in accordance with the change in water pressure and the resultant variation in ice pressure against the bed (Fig. 4). The focus here will be on the effect of an instantaneous decrease in cavity water pressure from the steady value of 2.1 to $1.5 \mathrm{MPa}$. Contours of $\sigma_{1}$ and $\sigma_{2}$ for $P_{\mathrm{w}}=1.5 \mathrm{MPa}$ are shown in Figure $6 \mathrm{~d}$ and $\mathrm{e}$. The reduction in water pressure increases $\sigma_{1}$ and decreases $\sigma_{2}$ over most of the step, resulting in larger principal stress differences than those produced under steady water pressure. This is due to the increase in ice pressure against the step's upper surface, together with the reduction in water pressure against its lee sur- 
face. As the water pressure in the lee of the step falls and ice pressure normal to the step's upper surface increases, vertical compressive stresses in the rock dominate horizontal compressive stresses, rotating the trajectory of the most compressive principal stress more nearly vertical (Fig. 6f). With higher water pressure in the cavity, normal pressures against the upper and lee surfaces of the step are more nearly equal and trajectories of $\sigma_{1}$ tend to dip more uniformly up-glacier.

\section{Fracture criterion}

The theory of Griffith (1924) will be used to assess the likelihood of fracture from the bedrock stresses. Unlike the Coulomb criterion, it directly addresses the mechanism of crack growth in brittle materials. In addition, numerically intensive alternatives involving the calculation of stress intensities for mixed-mode crack propagation under compressive conditions (e.g. Ingraffea and Heuze, 1980) are avoided.

The Griffith (1924) criterion defines the state of stress necessary to induce fracture growth from the tips of minute, pre-existing cracks in a material. Such cracks pervade all rocks in the Earth's upper crust. Under compressive conditions, tensile stresses may develop locally near the tips of favorably oriented cracks. These stresses are largest at crack surfaces, their magnitude depending upon the curvature and length of the crack tip, as well as on the nature of the remote stresses. Fracture is initiated at or near the tips of cracks when tensile stresses exceed some critical value. The critical stress for fracture propagation can be equated with the uniaxial tensile strength of the rock, $T_{0}$, determined from uniaxial tests. The fracture criterion, therefore, is expressed in terms of $T_{0}$ and the principal stresses and is of the form:

$$
\begin{array}{cc}
\frac{\left(\sigma_{1}-\sigma_{2}\right)^{2}}{8\left(\sigma_{1}+\sigma_{2}\right)}=T_{0} \quad \text { if } \sigma_{1}+3 \sigma_{2}>0 \\
\sigma_{2}=-T_{0} \quad \text { if } \sigma_{1}+3 \sigma_{2}<0 .
\end{array}
$$

The condition $\sigma_{1}+3 \sigma_{2}>0$ defines a stress state that is essentially compressive (Paterson, 1978). Unstable crack growth begins when criterion $(2 \mathrm{a})$ or $(2 \mathrm{~b})$ is satisfied, but much slower stable (sub-critical) crack growth will occur when tensile stresses are less than $T_{0}$ depending upon the crack length, temperature, pressure and chemical environment (see Atkinson (1984) for a review). These conditions are poorly constrained and thus predicting the state of stress under which fracture will occur is difficult. However, the criterion is adequate for comparing the propensity for fracture under contrasting stress fields.

Unfortunately, the Griffith criterion provides little insight into the orientation of macroscopic failure surfaces. As fractures grow from the tips of micro-cracks, local stress patterns around individual cracks begin to interfere with each other, rendering Griffith's treatment invalid. Final failure surfaces presumably result from the coalescence of these cracks (Murrell, 1971; Hallbauer and others, 1973).

Despite the local re-orientation of stresses that occurs as cracks propagate and coalesce, a substantial amount of empirical evidence suggests that fracture paths can be approximated from the stress state immediately prior to crack propagation. Studies of contact-induced fracture in glass (Frank and Lawn, 1967) and rocks (Lindquist and others, 1984) show that fractures lie approximately parallel to the most compressive principal stress of the pre-fracture stress field. In triaxial compression tests, fractures often form $20-30^{\circ}$ from the most compressive principal stress, with the size of the angle being proportional to the confining pressure on the specimen (Paterson, 1978 , p. 17). It is probably safe to assume, therefore, that fractures will lie at a relatively small angle $\left(<30^{\circ}\right)$ to $\sigma_{1}$ of the pre-fracture stress field. More specific predictions cannot be made, however, particularly in the light of the structural anisotropy in many rocks. Trajectories of $\sigma_{1}$ were approximately vertical in both the steady and transient cases considered here (Fig. 6c and $\mathrm{f}$ ), and thus predominantly vertical fractures are expected. A shear stress applied to the bedrock surface rotates the dip of $\sigma_{1}$ trajectories down-glacier. However, this effect is small unless the shear stress against the bed is comparable in magnitude to the normal stress.

In order to evaluate the likelihood of rock fracture from the principal stresses, a fracture index, $T_{\mathrm{g}}$, representing the tensile stress near favorably oriented cracks
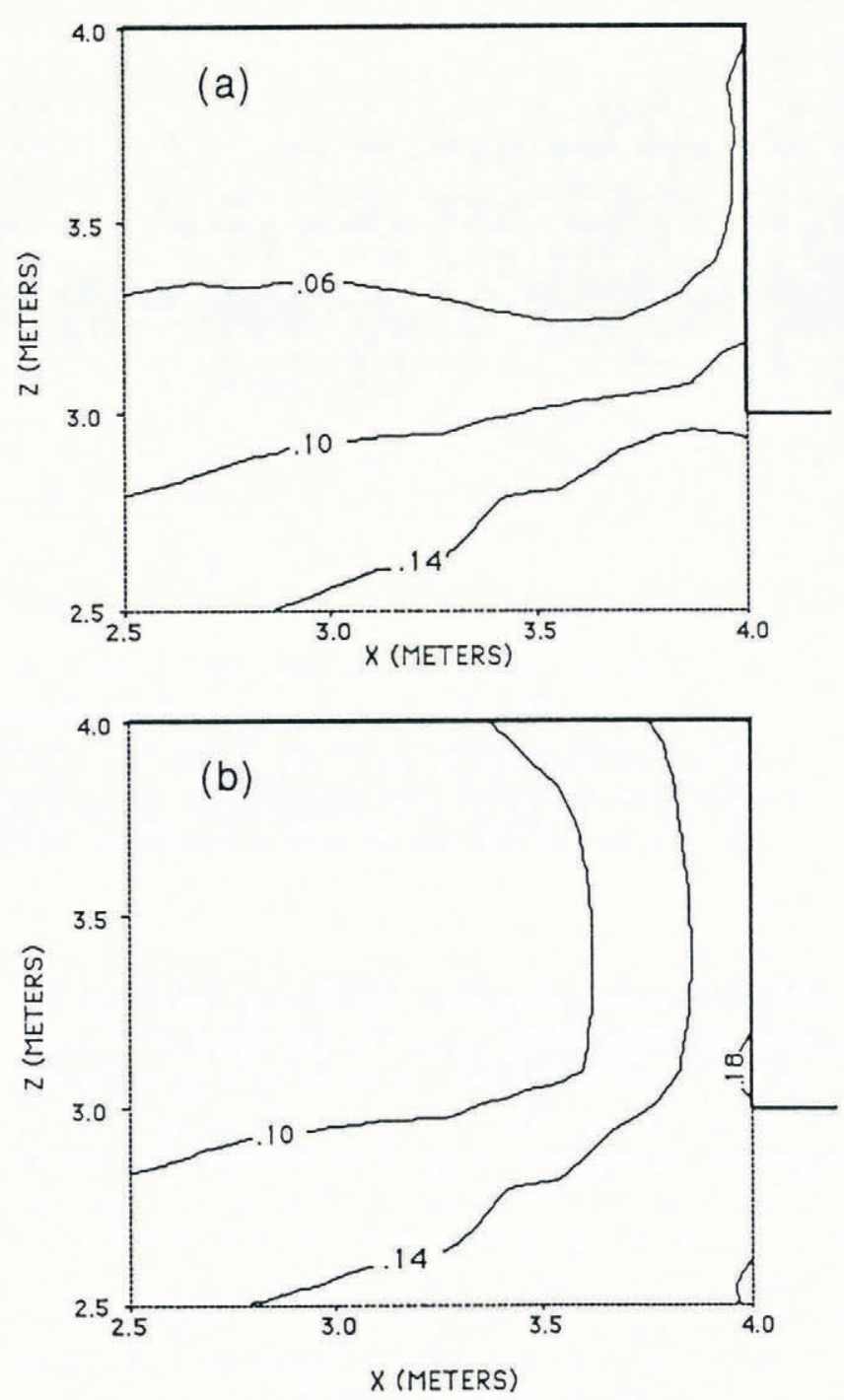

Fig. 7. Contours of $T_{g}$ when (a) the cavity is steady at a water pressure of $2.1 \mathrm{MPa}$, and (b) the cavity water pressure is reduced to 1.5 MPa. Step surface is delineated with a bold line. Values of $T_{g}$ are in MPa. 
that result from the prescribed principal stresses, can be substituted for $T_{0}$ in the fracture criterion (Equations (2)) and treated as a dependent variable (Johnson, 1975). Principal stresses are used to determine $T_{\mathrm{g}}$ from the criterion equation for each element in the modeled section. Large values of $T_{\mathrm{g}}$ denote a greater propensity for rock fracture and, where $T_{\mathrm{g}}>T_{0}$, unstable crack propagation is expected. Note that $T_{\mathrm{g}}$ becomes larger as principal stress differences increase and becomes smaller as mean stress increases (Equation (2a)). $T_{\mathrm{g}}$ is contoured in Figure $7 \mathrm{a}$ and $\mathrm{b}$ for the steady cavity $P_{\mathrm{w}}=21$ bar) and for the case of the rapid decline in water pressure to 1.5 $\mathrm{MPa}$. No internal water pressure is assumed to exist within micro-cracks. Throughout most of the step the tendency for crack propagation is increased by the reduction in water pressure. In the outer $0.5 \mathrm{~m}$ closest to the cavity where quarrying might be considered to be most likely, values of $T_{\mathrm{g}}$ are over twice as large in the transient case. There is also a tendency in both the steady and transient cases for $T_{\mathrm{g}}$ to increase with depth in the rock. This results mainly from the general decrease in the mean compressive stress with depth.

Values of $T_{\mathrm{g}}$ in Figure 7 are smaller than values of $T_{0}$ obtained from uniaxial tensile tests, which for most rocks exceed 1.0 MPa (Jaeger and Cook, 1979, p. 190), and thus in this example unstable fracture propagation is unlikely. However, if there are pre-existing, centimeterscale fractures in the rock (e.g. Peng, 1975), values of $T_{0}$ may be reduced by more than an order of magnitude, and crack extension should occur in some sandstones, limestones and marbles. In addition, much slower, subcritical fracture propagation is expected due to stress corrosion, which may reduce values of $T_{\mathrm{g}}$ necessary to cause fracture by as much as a factor of 5 (Atkinson, 1984).

\section{Effect of water pressure within cracks}

Subglacial bedrock is likely to be saturated with water. Because subglacial water pressure may frequently be a significant fraction of the ice-overburden pressure, internal water pressure within cracks, $P_{\mathrm{c}}$, may be large and play an important role in fracturing bedrock. The same failure criterion applies, except that $\sigma_{1}$ and $\sigma_{2}$ are replaced by the effective principal stresses $\sigma_{1}{ }^{\prime}$ and $\sigma_{2}{ }^{\prime}$ where

$$
\sigma_{1}^{\prime}=\sigma_{1}-P_{\mathrm{c}}
$$

and

$$
\sigma_{2}{ }^{\prime}=\sigma_{2}-P_{c} .
$$

It is assumed that cracks are sufficiently isolated from each other so that remote stresses applied to an individual crack are not affected by other cracks in the rock. It is a good assumption for crystalline rocks in the light of their low porosities but probably is a poor assumption for certain sedimentary rocks. The assumption that cracks are widely spaced and thus do not interfere with each other was also made by Griffith (1924) when the local stress field around an individual arbitrarily oriented crack was determined in the derivation of Equations (2).

Values of $T_{\mathrm{g}}$ were recalculated taking into consideration the effect of water pressure in cracks by substituting Equations (3) into Equations (2) and calculating effective principal stresses. For the steady cavity, it is assumed

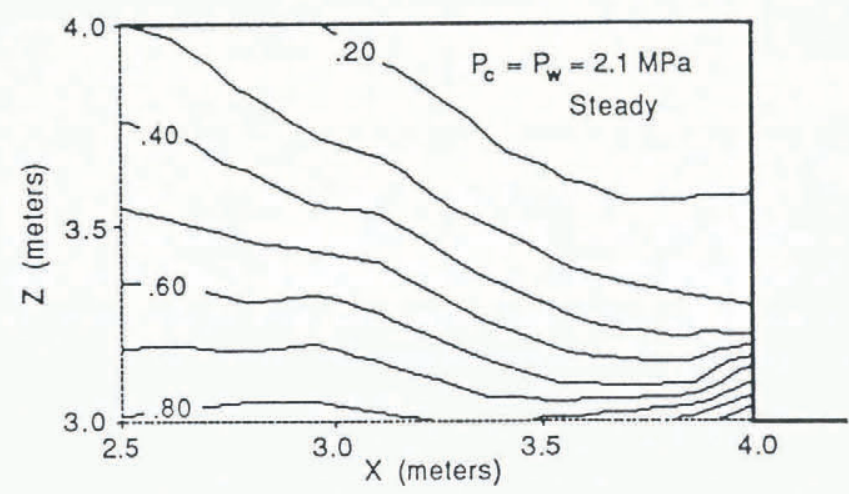

(a)

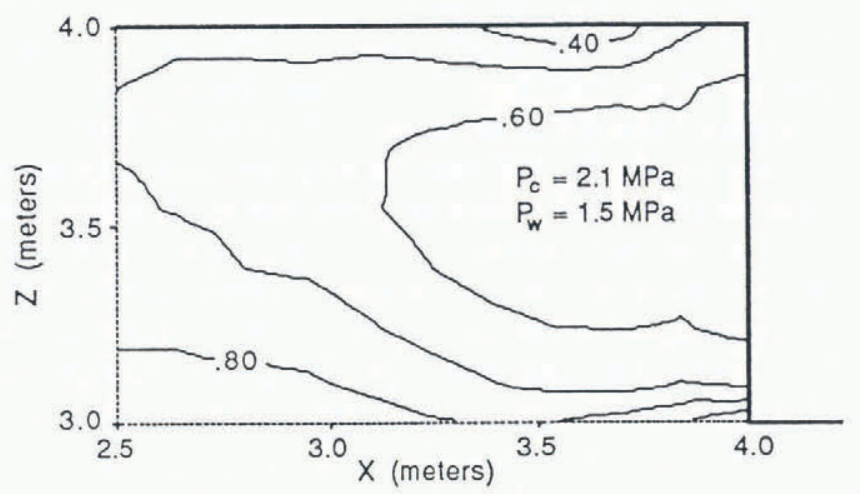

(b)

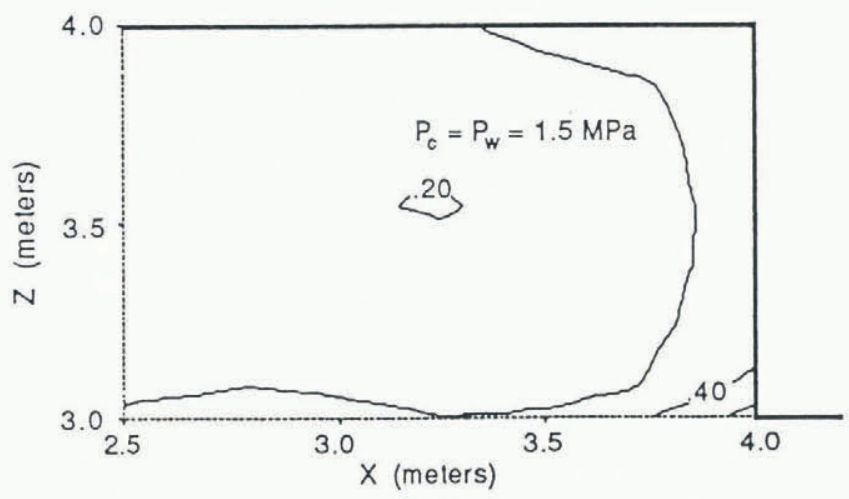

(c)

Fig. 8. Contours of $T_{g}$ when (a) the cavity is steady at a water pressure of $2.1 \mathrm{MPa}$ and $P_{c}=2.1 \mathrm{MPa}$, (b) the cavity water pressure is reduced to $1.5 \mathrm{MPa}$ and $P_{c}=2.1 \mathrm{MPa}$, and (c) the cavity water pressure is reduced to $1.5 \mathrm{MPa}$ and $P_{c}=1.5 \mathrm{MPa}$. Step surface is delineated with a bold line. Values of $T_{g}$ are in $\mathrm{MPa}$.

that the crack water pressure has had sufficient time to equilibrate with the water pressure in the cavity. Thus, $P_{\mathrm{c}}=P_{\mathrm{w}}=2.1 \mathrm{MPa}$. Values of $T_{\mathrm{g}}$ (Fig. 8a) indicate that by reducing the effective mean compressive stress on microcracks in the step, the water pressure in cracks results in local tensile stresses at crack tips that are up to ten times greater than in the case of unsaturated bedrock (Fig. 7a). In this case, values of $T_{\mathrm{g}}$ are large enough to cause sub-critical crack extension in most sedimentary rocks and some crystalline rocks, particularly if there are centimeter-scale pre-existing cracks in the rock (e.g. Peng, 1975; Labuz and others, 1985). 
A critical problem is estimating how the water pressure within cracks changes in response to variations in subglacial water pressure. An abrupt reduction in the cavity water pressure from the steady value should result in a time-dependent change in the water pressure within cracks in the step. Rigorous analysis of the rate of this decay is difficult due to the step geometry and the dependence of the rock's hydraulic properties on the change in ice pressure that accompanies the decline in $P_{\mathrm{w}}$. The main concern here, however, is grossly constraining the length of time that water pressure in cracks can remain out of equilibrium with the subglacial water pressure. A reasonable approximation is that the time necessary for water-pressure relaxation in cracks scales with $h^{2} / D$, where $h$ is the step height and $D$ is the hydraulic diffusivity of the rock (see Carslaw and Jaeger (1959) for analogous treatments of transient heat flow). Values of $D$ vary widely for different rock types, primarily as a function of differences in rock permeability. Unfractured igneous and metamorphic rocks may have diffusivities as low as $7 \times 10^{-7} \mathrm{~m}^{2} \mathrm{~s}^{-1}$, whereas a typical diffusivity for sedimentary rocks is $10 \mathrm{~m}^{2} \mathrm{~s}^{-1}$ (Freeze and Cherry, 1979). Therefore, the time required for $P_{\mathrm{c}}$ to equilibrate with changes in subglacial water pressure throughout the step may be on the order of several weeks or fractions of a second. Thus, for relatively impermeable rocks, typical diurnal water-pressure fluctuations beneath glaciers (Kamb and others, 1985; Iken and Bindschadler, 1986; Hooke and others, 1987, 1989) may produce large gradients in $P_{\mathrm{c}}$ very near cavities, without significantly affecting $P_{\mathrm{c}}$ in bedrock that is slightly removed from cavities. In more permeable rocks, however, $P_{\mathrm{c}}$ throughout subglacial bedrock may vary roughly simultaneously with subglacial water pressure.

In order to analyze the effect of a rapid decrease in $P_{\mathrm{w}}$ on rock fracture, two end members of the continuum of crack water-pressure responses are considered: (1) the rock is sufficiently impermeable so that $P_{\mathrm{c}}$ remains at essentially the steady value throughout the step after a reduction in $P_{\mathrm{w}}$, and (2) the rock is sufficiently permeable so that changes in $P_{\mathrm{c}}$, throughout the step occur simultaneously with changes in $P_{\mathrm{w}}$. Note that in both of these ideal cases $P_{\mathrm{c}}$ is uniform throughout the step, and therefore the possible effect of transient hydraulic gradients on rock fracture (Rice and Cleary, 1976) is not considered. If the water pressure in cracks throughout the step remains at $2.1 \mathrm{MPa}$ while the cavity water pressure falls to $1.5 \mathrm{MPa}$, the tendency for crack propagation, relative to the steady case when the rock is water-saturated, is increased over most of the step, in some areas by as much as a factor of 3 (Fig. 8b). This is consistent with earlier calculations when it was assumed that $P_{\mathrm{c}}=0$ (Fig. 7). However, if $P_{\mathrm{c}}$ varies in phase with $P_{\mathrm{w}}$ and both simultaneously fall from 2.1 to $1.5 \mathrm{MPa}$, the effect on crack propagation is less distinct (Fig. $8 \mathrm{c}$ ). $T_{\mathrm{g}}$ is slightly increased relative to the steady case in the upper corner of the step, but elsewhere $T_{\mathrm{g}}$ is slightly less than in the steady case. In this situation, the decrease in the crack water pressure increases the effective mean compressive stress on cracks sufficiently to counteract the effect of the increase in $\sigma_{1}-\sigma_{2}$ that occurs when $P_{\mathrm{w}}$ is reduced. Thus, the increase in the propensity for bedrock fracture that occurs with transient decreases in subglacial water pressure should be greater in less permeable rocks.

\section{CONCLUSIONS}

Subglacial water pressure influences rock fracture in two ways: it affects the distribution and magnitude of stress against the bedrock surface and the internal water pressure within fractures and microscopic cracks in the rock.

When water pressure falls in a subglacial cavity, some of the weight of the glacier formerly supported by pressurized water is shifted to the bedrock surface, which increases the ice pressure against the bed up-glacier from the cavity. This effect has been illustrated for the bedrock step considered here (Fig. 4) and for sinusoidal bed undulations (Röthlisberger and Iken, 1981). The increase in ice pressure against the bed, together with the decrease in water pressure against the lee surface of the bedrock irregularity, increases the difference between principal stresses in the rock. The result is an increase in the tendency for growth of pre-existing cracks in a direction roughly parallel to the most compressive principal stress, producing approximately vertical fractures in the case of a bedrock step. This effect may be partly or wholly counteracted if the rock permeability is sufficiently high so that the water pressure in cracks is reduced roughly simultaneously with the water pressure in cavities. In this case, the effective mean compressive stress on cracks increases as the crack water pressure is reduced, inhibiting crack growth.

Macroscopic fractures produced subglacially, probably acting in conjunction with preglacial joints and bedding planes, will isolate some rock fragments from the surrounding bedrock. Unlike subglacial rock fracture, the removal of loosened rock fragments is expected to be accelerated during periods of increasing subglacial water pressure and low effective stress. During periods of increasing water pressure, pressure-release freezing between ice and parts of the bed may occur as glacier sliding is accelerated, thereby increasing bed-parallel stresses on detached rock fragments (Robin, 1976; Röthlisberger and Iken, 1981). Accelerated glacier sliding should also increase the drag on rough fragment surfaces exposed to ice. Concurrently, effective stresses should be reduced between fragments and adjacent rock as the water pressure in fractures increases, reducing the frictional resistance to fragment dislodgement. This effect should be reinforced by the reduction in ice pressure against the bed that occurs as water pressure in cavities increases.

Thus, fluctuations in subglacial water pressure may result in periods of accelerated crack propagation in intact bedrock that alternate with periods of accelerated rock-fragment removal from the bed. This suggests that as water pressure fluctuates beneath glaciers, bedrock in zones of ice-bed separation subject to large waterpressure fluctuations will be quarried faster than in other areas where, due to differences in the local drainage system, water-pressure fluctuations are smaller.

\section{ACKNOWLEDGEMENTS}

I am grateful to R. Hooke for valuable guidance throughout the course of this study and for reviewing a preliminary version of this paper. Suggestions made by B. Hallet, A. Iken and an anonymous reviewer substantially im- 
proved the paper. J. Paetz helped solve numerous computer problems. Funds for computing were provided, in part, by the Minnesota Supercomputer Institute. I also thank P. Hudleston, H. Wright, J. Labuz and W. Gerberich for reviewing a preliminary version of this paper as a section of my doctoral thesis at the University of Minnesota.

\section{REFERENCES}

Addison, K. 1981. The contribution of discontinuous rock-mass failure to glacier erosion. Ann. Glaciol., 2, 3-10.

Anderson, R. S., B. Hallet, J. Walder and B. F. Aubry. 1982. Observations in a cavity beneath Grinnell Glacier. Earth Surface Processes and Landforms, $7(1), 63-70$.

Atkinson, B. K. 1984. Subcritical crack growth in geological materials. J. Geophys. Res., 89(B6), 4077-4114.

Carslaw, H.S. and J.C. Jaeger. 1959. Conduction of heat in solids. Oxford, Clarendon Press.

Crosby, I. B. 1945. Glacial erosion and the buried Wyoming valley of Pennsylvania. Bull. Geol. Soc. Am., 56, 389-400.

Frank, F.C. and B.R. Lawn. 1967. On the theory of Hertzian fracture. Proc. R. Soc. London, 299, 291306.

Freeze, R. A. and J. A. Cherry. 1979. Groundwater. Englewood Cliffs, NJ, Prentice-Hall.

Griffith, A. A. 1924. The theory of rupture. In Biezeno C. B. and J. M. Burgers, eds. Proc. First Inter. Congr. Appl. Mech. Delft, J. Waltman, Jr.

Gustafson, R. J., D. J. Hansen and D. A. Folen. 1977. Finite element method package. St. Paul, MN, University of Minnesota.

Hallbauer, D. K., H. Wagner and N. G. W. Cook. 1973. Some observations concerning the microscopic and mechanical behavior of quartzite specimens in stiff, triaxial compression tests. Int. J. Rock Mech. Min. Sci. Geomech. Abstr. 10, 713-726.

Hallet, B. 1979. A theoretical model of glacial abrasion. J. Glaciol., 23(89), 39-50.

Hallet, B. and R. S. Anderson. 1982. Detailed glacial geomorphology of a proglacial bedrock area at Castleguard Glacier, Alberta, Canada. Z. Gletscherkd. Glazialgeol., 16(2), 1980, 171-184.

Hanson, B. 1985. Climate sensitivity of a numerical model of ice sheet dynamics and thermodynamics. Cooperative thesis No. 91, National Center for Atmospheric Research, Boulder, CO.)

Hooke, R. LeB. 1981. Flow law for polycrystalline ice in glaciers: comparison of theoretical predictions, laboratory data, and field measurements. Rev. Geophys. Space Phys., 19(14), 664-672.

Hooke, R. LeB., P. Holmlund and N. R. Iverson. 1987. Extrusion flow demonstrated by bore-hole deformation measurements over a riegel, Storglaciären, Sweden. J. Glaciol., 33(113), 72-78.

Hooke, R. LeB., P. Calla, P. Holmlund, M. Nilsson and A. Stroeven. 1989. A 3 year record of seasonal variations in surface velocity, Storglaciären, Sweden. J. Glaciol., 35(120), 235-247.
Iken, A. 1981. The effect of the subglacial water pressure on the sliding velocity of a glacier in an idealized numerical model. J. Glaciol., 27(97), 407-421.

Iken, A. and R. A. Bindschadler. 1986. Combined measurements of subglacial water pressure and surface velocity at Findelengletescher, Switzerland: conclusions about drainage system and sliding mechanism. J. Glaciol., 32(110), 101-119.

Ingraffea, A. R. and F. E. Heuze. 1980. Finite element models for rock fracture mechanics. Int. J. Numer. Anal. Methods Geomech., 4, 25-43.

Jaeger, J. C. and N. G. W. Cook. 1979. Fundamentals of rock mechanics., New York, Chapman and Hall.

Johnson, C.B. 1975. Characteristics and mechanics of formation of glacial arcuate abrasion cracks. (Ph.D. thesis, Pennsylvania State University.)

Kamb, W.B. 1987. Glacier surge mechanism based on linked cavity configuration of the basal water conduit system. J. Geophys. Res., 92(B9), 9083-9100.

Kamb, W. B. and 7 others. 1985. Glacier surge mechanism: 1982-1983 surge of Variegated Glacier, Alaska. Science, 227(4686), 469-479.

Labuz, J.F., S. P. Shah and C. H. Downing. 1985. Experimental analysis of crack propagation in granite. Int. J. Rock Mech. Min. Sci. Geomech. Abstr., 22(2), 85-98.

Lindquist, P. A., H. H. Lai and O. Alm. 1984. Indentation fracture developments in rock continuously observed with a scanning electron microscope. Int. J. Rock Mech. Min. Sci. Geomech. Abstr., 21(4), 165-182.

Matthes, F.E. 1930. Geological history of the Yosemite Valley. U.S. Geol. Surv. Prof. Pap. 160.

Morland, L. W. and E. M. Morris. 1977. Stress fields in an elastic bedrock hump due to glacier flow. J. Glaciol., 18(78), 67-75.

Murrell, S. A.F. 1971. Micromechanical basis of the deformation and fracture of rocks. In Te'eni, M., ed. Structure, solid mechanics, and engineering design. London, Wiley-Interscience.

Nye, J.F. 1965. The flow of a glacier in a channel of rectangular, elliptic or parabolic cross-section. J. Glaciol., 5(41), 661-690.

Nye, J. F. 1969. A calculation on the sliding of ice over a wavy surface using a Newtonian viscous approximation. Proc. R. Soc. London, Ser. A, 311, 445-467.

Paterson, M.S. 1978. Experimental rock deformation - the brittle field. Berlin, etc., Springer-Verlag.

Peng, S.S. 1975. A note on fracture propagation and time-dependent behavior of rocks in uniaxial tension. Int. J. Rock Mech. Min. Sci. Geomech. Abstr., 12, $125-127$.

Rastas, J. and M. Seppälä. 1981. Rock jointing and abrasion forms on roches moutonnées, SW Finland. Ann. Glaciol., 2, 159-163.

Rice, J. R. and M. P. Cleary. 1976. Some basic diffusion solutions for fluid-saturated elastic media with compressible constituents. Rev. Geophys. Space Phys., 14(2), 227-241.

Robin, G. de Q. 1976. Is the basal ice of a temperate glacier at the pressure melting point? J. Glaciol., 16(74), 183-196. 
Röthlisberger, H. and A. Iken. 1981. Plucking as an effect of water-pressure variations at the glacier bed. Ann. Glaciol, 2, 57-62.

Sharp, M. 1982. Modifications of clasts in lodgement tills by glacial erosion. J. Glaciol., 28(100), 475-481.
Zumberge, J.H. 1955. Glacial erosion in tilted rock layers. J. Geol., 63(2), 149-158.

The accuracy of references in the text and in this list is the responsibility of the authors, to whom queries should be addressed.

MS received 12 September 1989 and in revised form 1 October 1990 